\title{
Ambient vibration analysis of an unstable mountain slope
}

\section{Journal Article}

\section{Author(s):}

Burjánek, Jan; Gassner-Stamm, Gabriela; Poggi, Valerio; Moore, Jeffrey R.; Fäh, Donat

Publication date:

2010-02

Permanent link:

https://doi.org/10.3929/ethz-b-000413794

Rights / license:

In Copyright - Non-Commercial Use Permitted

Originally published in:

Geophysical Journal International 180(2), https://doi.org/10.1111/j.1365-246X.2009.04451.x 


\title{
Ambient vibration analysis of an unstable mountain slope
}

\author{
Jan Burjánek, ${ }^{1}$ Gabriela Gassner-Stamm, ${ }^{1}$ Valerio Poggi, ${ }^{1}$ Jeffrey R. Moore ${ }^{2}$ \\ and Donat Fäh ${ }^{1}$ \\ ${ }^{1}$ Swiss Seismological Service, Institute of Geophysics, ETH Zürich, Sonneggstrasse 5, CH-8092 Zürich, Switzerland. E-mail: burjanek@sed.ethz.ch \\ ${ }^{2}$ Geological Institute, ETH Zürich, Sonneggstrasse 5, CH-8092 Zürich, Switzerland
}

Accepted 2009 November 10. Received 2009 October 26; in original form 2009 June 17

\begin{abstract}
S U M M A R Y
A field experiment with small aperture seismic arrays was performed on the unstable rock slope above the village of Randa in the southern Swiss Alps. The aim of this experiment was to constrain the seismic response of a potential future rockslide using ambient vibration recordings. Weak seismic events were identified on the recordings and site-to-reference spectral ratios were calculated using a reference site located on the stable part of the slope. Spectral ratios of up to 30 were observed at sites located within the unstable portion of the slope. A strong variation of spectral ratios with azimuth indicates a directional site effect. Neither amplification nor directionality were observed at sites located in the stable part of the slope. Furthermore, time-frequency polarization analysis of the ambient noise was performed to provide robust estimates of frequency dependent directions of the maximum polarization. It was found that the unstable part of the slope vibrates within a narrow range of directions (130 \pm $10^{\circ}$ ) for the frequency range centred around $5 \mathrm{~Hz}$. The polarization directions estimated from ambient seismic vibrations are in good agreement with the deformation directions obtained by geodetic and in situ measurements. No directionality of ambient vibrations was observed at sites within the stable part of the slope.
\end{abstract}

Key words: Wavelet transform; Site effects; Wave propagation.

\section{INTRODUCTION}

Coseismic landslides, including rockfall and rockslides, accompany almost all major earthquakes striking steep terrain and are among the most widespread and destructive secondary effects of seismic shaking (Keefer 1984). A number of coseismic slope instabilities in the Matter Valley of the Switzerland were documented by Fritsche et al. (2006), in response to the 1855 Visp earthquake $\left(M_{\mathrm{w}} \sim 6.4\right)$. These events and their consequences illustrate the need to better understand the seismic response of rock slopes as a key point for the mitigation of earthquake hazard. A simple pseudostatic approach (Terzaghi 1950) and more advance Newmark sliding block models (Newmark 1965), are commonly used to analyse seismic slope stability. However, these methods ignore many aspects of the seismic response of landslides, for example, interactions between incoming waves and the topography or internal structure of the landslide. Thus, direct numerical modelling of dynamic strains within the unstable rock mass are of general interest. Unfortunately, such detailed models require a broad range of data to be well constrained, which makes their cost and effort significant (e.g. Willenberg et al. 2008a,b).

This paper describes seismic array measurement of ambient noise performed on the slowly moving rock slope instability above the village of Randa (Canton Valais) in the southern Swiss Alps. The aim of this experiment was to explore whether we could gain useful information about the structure and seismic response of the potential rockslide from ambient vibration recordings.

Array measurement of ambient noise is a relatively inexpensive technique for estimating shear wave velocity profiles (e.g. Tokimatsu 1997; Okada 2003; Kind et al. 2005). Danneels et al. (2008) successfully applied this technique to estimate shear wave velocities in an earth-flow area in Kyrgyzstan. The experiment presented here was designed to test the technique within an unstable rock slope, even though a number of assumptions were not fulfilled for application of ambient vibration array methods (steep slope, strong lateral inhomogeneities, open cracks, etc.). To date, we have been unsuccessful in interpreting the acquired data using the $f-k$ and the SPAC methods, which could be related to the short duration of the recordings. In particular, parts of the time-series were adversely affected by people performing differential GPS measurements of the sensor positions. As these time windows could not be analysed, the usable time-series were relatively short. Another limiting factor was the small aperture of deployed arrays $(<150 \mathrm{~m})$, which limited measurement of velocity in the stable rock mass ( $P$-wave velocities $>3000 \mathrm{~m} \mathrm{~s}^{-1}$ reported by Spillmann et al. (2007). On the other hand, $P$-wave velocities as low as $500 \mathrm{~m} \mathrm{~s}^{-1}$ were observed at shallow depths $(<25 \mathrm{~m})$ in the unstable area where highly fractured rock is present (Spillmann et al. 2007). Thus, expected surface wave 
velocities should be within the resolution limits of the array in the unstable area.

Nevertheless, it was possible to retrieve useful information by means of other methods. We identified weak seismic events on the recordings and calculated site-to-reference spectral ratios. From the map of spectral ratios we can distinguish stable from unstable portions of the rock slope. Moreover, we were able to estimate possible ground amplification within the unstable area. We also identified clear directivity and performed polarization analysis of the ambient noise. A specific pattern of directivity was discovered and compared against direct measurements of slope deformation.

\section{RANDA STUDY SITE}

The Randa study site lies above and behind the scarp (Fig. 1) created after two large rockslide events in 1991 (Schindler et al. 1993). The remaining rock mass above the scarp is currently moving at rates up to $2 \mathrm{~cm} \mathrm{yr}^{-1}$ and could result in a future rockslide with a volume of $\sim 5$ million $\mathrm{m} 3$. The site has been extensively investigated utilizing broad spectrum of methods (Green et al. 2006; Willenberg et al. 2008a, and references therein), providing the unique opportunity to test new techniques in a well-characterized environment. The large set of available data makes it possible to predict the seismic response of key structures in a quantitative way, and to interpret seismic observations at the site.

\section{FIELD EXPERIMENT}

Fourteen three-component velocity sensors with an eigenperiod of $5 \mathrm{~s}$ were used together with 12 digital seismic systems (six channels per instrument) to record ground vibrations on the slope. The field experiment was carried out during one day. Compass-oriented sensors were placed on metal trihedrons in shallow holes, removing superficial unconsolidated soil. The error of the sensor orientation was less then $\pm 5^{\circ}$. The precise positions of the sensors were measured with differential GPS. We progressively deployed three arrays with apertures up to $150 \mathrm{~m}$ (Fig. 1). The first array was deployed on a small bench above the scarp and within the unstable rock mass. The third array was placed on an upper (60 $\mathrm{m}$ altitude difference) plateau which is currently stable. The second array was located between these two plateaus. Both the first and third arrays consisted of two subarrays. Each array (and subarray) recorded for at least 30 min. A reference station was deployed on the upper plateau, recording continuously throughout the day.

\section{ANALYSIS OF RECORDINGS}

\subsection{Site-to-reference spectral ratios}

A number of seismic events were identified on the array recordings by visual inspection. The origin of these events is not accurately known. One hypothesis is that these signals were created by collapsing ice from nearby glaciers and cornices, which was heard during the field measurement campaign. We did not find such signals on continuous recordings obtained at nearby stations of the Swiss Digital Seismic Network (the closest permanent station, MKK, at a distance of $16 \mathrm{~km}$ was out of order at the time). The apparent velocity of these signals was found using beamforming to be beyond the resolution limits of the arrays. As the amplitudes are very similar and the waveforms coherent, the distance to the source of these signals is at least one multiple of the array aperture.

Three events were observed on the recordings of Array 2 and six events on the recordings of the larger subarray of Array 3. All events were recorded by the reference station. No events were identified on recordings of the smallest rings - first subarrays - of Array 1 and Array 3.

We calculated site-to-reference spectral ratios for these events (Borcherdt 1970), under the assumption that the sources of these signals are far from the array (especially as compared to referencearray station distances) and omitting both source radiation directivity and path effects. Raw velocity recordings were corrected for baseline shift. No instrumental correction was applied, as just one type of instrument was used and no data at periods longer than the eigenperiod of the sensor were interpreted. An example event
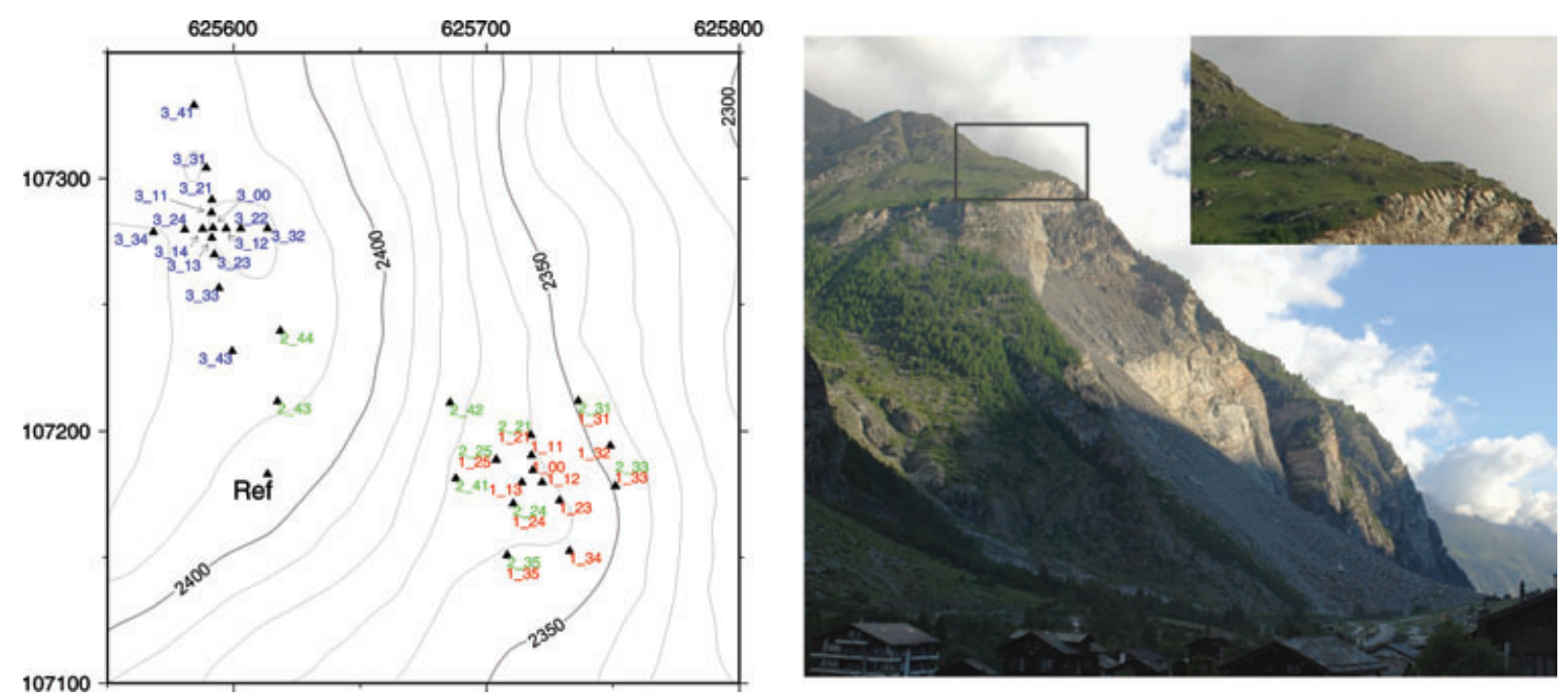

Figure 1. Configuration of the seismic arrays is shown at left-hand side (red: Array 1; green: Array 2; blue: Array 3). Naming conventions: 1_32 denotes station RAN1_32, that is, Array 1, station 32. Some stations of Array 2 shared positions with stations of Array 1 and these stations have the same station number (e.g. RAN1_25 = RAN2_25). The coordinates are given in $\mathrm{m}$ of the Swiss Coordinate System. The photo on the right-hand side shows the scarp and debris cone of the 1991 rockslides (taken at Randa village, a view to the North). The study site is enlarged in the inset. The two plateaus where the arrays were deployed are distinguishable on the zoomed view. 


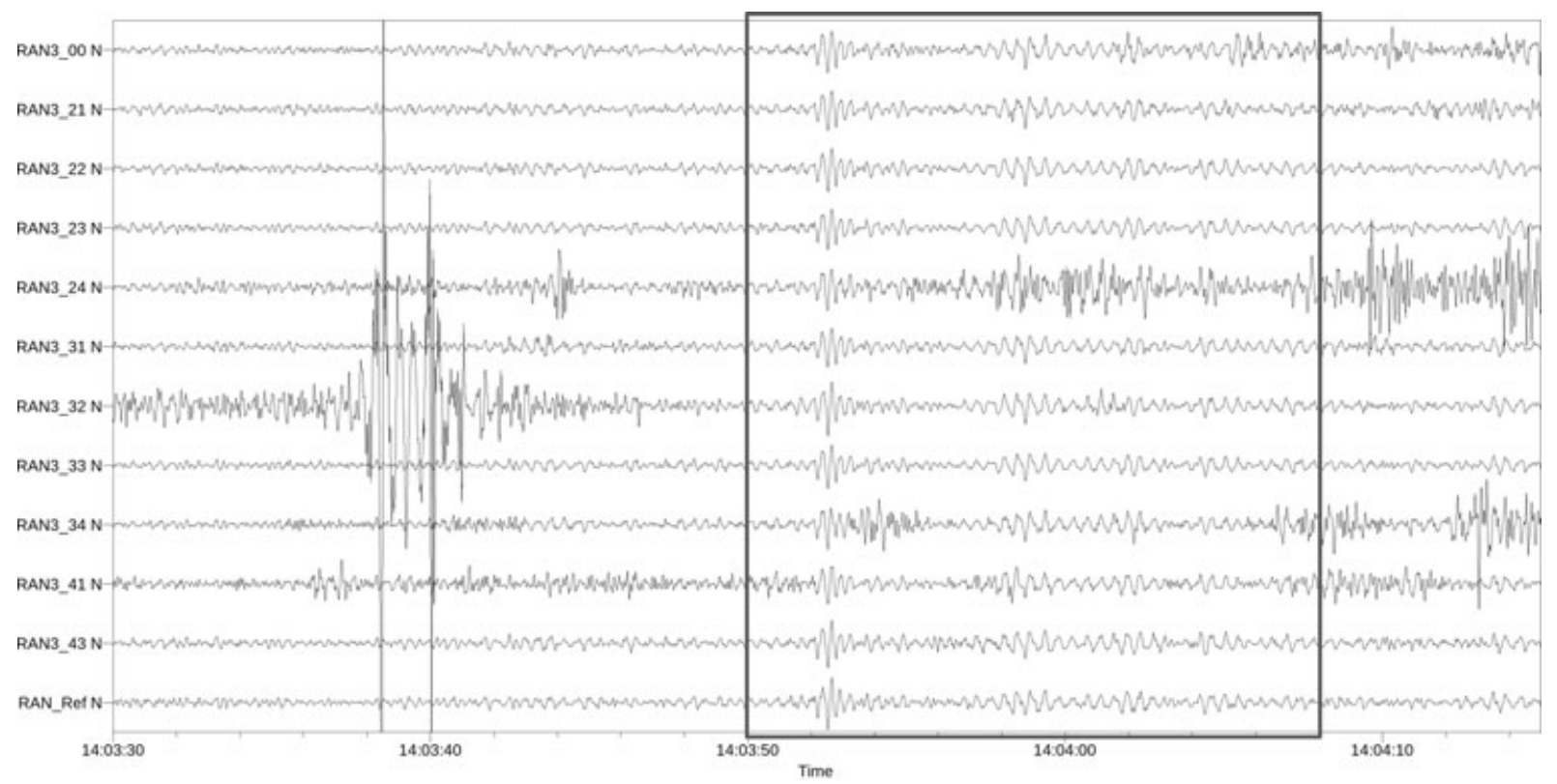

Figure 2. An example of a single event (in black frame) recorded by Array 3 . The North component of filtered (2-15 Hz) velocity recordings are presented. Seismograms are normalized to a value common for all recordings (i.e. no scaling across seismograms). The strong disturbance prior to the event on the RAN3_32 trace is caused by a person measuring the sensor location.

time history recorded by Array 3 is shown in Fig. 2. Event recordings that were clearly affected by artificial noise (e.g. someone walking close to the sensor) were not considered. The amplitude spectra of the Fourier transform were smoothed using the window proposed by Konno \& Ohmachi (1998), with a bandwidth $b=20$, before calculating the spectral ratio. Horizontal recordings were progressively rotated with an azimuthal step of $5^{\circ}$, and spectral ratios calculated for each pair of horizontal components. The component at $125^{\circ}$ (measured from north) presented the highest absolute ratio (a factor of 30). It was found by trial and error that the spectral ratios are systematically stronger in the unstable part of the slope for orientations of $125 \pm 5^{\circ}$. Resulting spectral ratios for two horizontal components $\left(35^{\circ}\right.$ and $\left.125^{\circ}\right)$ are presented in Fig. 3. The frequency band was restricted to $2-15 \mathrm{~Hz}$, since the spectral ratios were stable across the events in this range. The geometric mean across events was also computed for both components. The mean from three values (in case of Array 2) is generally of low statistical significance, but still representative in this case since the scatter is not high.

An interpolated map of the mean spectral ratios for both horizontal components is presented in Fig. 4. The mean spectral ratio (MSR) is close to unity on the upper (stable) plateau (Array 3 and stations RAN2_43, RAN2_44) for both components and does not show any trend with frequency. On the lower (unstable) plateau (stations RAN2_21, RAN2_24, RAN2_25, RAN2_31, RAN2_33, RAN2_35), however, the MSR follows a trend in both the spatial and frequency domains. In particular, MSR gradually increases with frequency for both horizontal components towards the southwest, that is, towards the scarp of the 1991 rockslides. Concerning directionality, the MSR is significantly higher in the $125^{\circ}$ direction, with the exception of station RAN2_25. This station was positioned at the foot of the slope just outside the border of the unstable area proposed by Willenberg et al. (2008b). Station RAN2_31 shows a more complicated pattern: the $125^{\circ}$ component dominates up to $8 \mathrm{~Hz}$, while the $35^{\circ}$ component is stronger at higher frequencies. A likely explanation will be explored in the next section. Stations that were placed on the slope between the two plateaus (RAN2_41,
RAN2_42) show only a very slight increase of MSR with frequency. Such an increase fits the overall pattern of MSR gradually increasing from the upper to the lower plateau (Fig. 4). To summarize, MSR observed on the upper (stable) plateau shows qualitatively different behaviour compared to the lower (unstable) plateau (i.e. directivity and large absolute values).

We also attempted to estimate site-to-reference spectral ratios from ambient noise, but found the estimated power spectra of the noise unreliable. Particularly, the error of the estimated power spectra was large using both single taper windowing and even the multitaper method. This is primarily due to the short length of the undisturbed noise time-series available. It is therefore advisable to record longer time-series of undisturbed noise during future experiments (at least $1 \mathrm{hr}$ recommended).

\subsection{Polarization analysis of noise}

Since the site-to-reference spectral ratios showed significant directionality for some stations, we performed more detailed polarization analysis of the recorded ground motion. In this analysis, we process noise rather than the recorded seismic events. The results should therefore be more robust since longer time-series are processed and the problem of signal to noise ratio is alleviated. The procedure could be easily repeated for other sites in the future, as it does not depend on the occurrence of any seismic events. We focused only on the lower plateau, the unstable area, where directionality of the MSR was most pronounced. The noise recording from the reference station was also processed for comparison.

\subsubsection{Method}

We adopted and slightly generalized the method of complex particle motion polarization analysis introduced by Vidale (1986). This method is based on principal component analysis of the coherency matrix (i.e. complex covariance matrix), which is computed from 

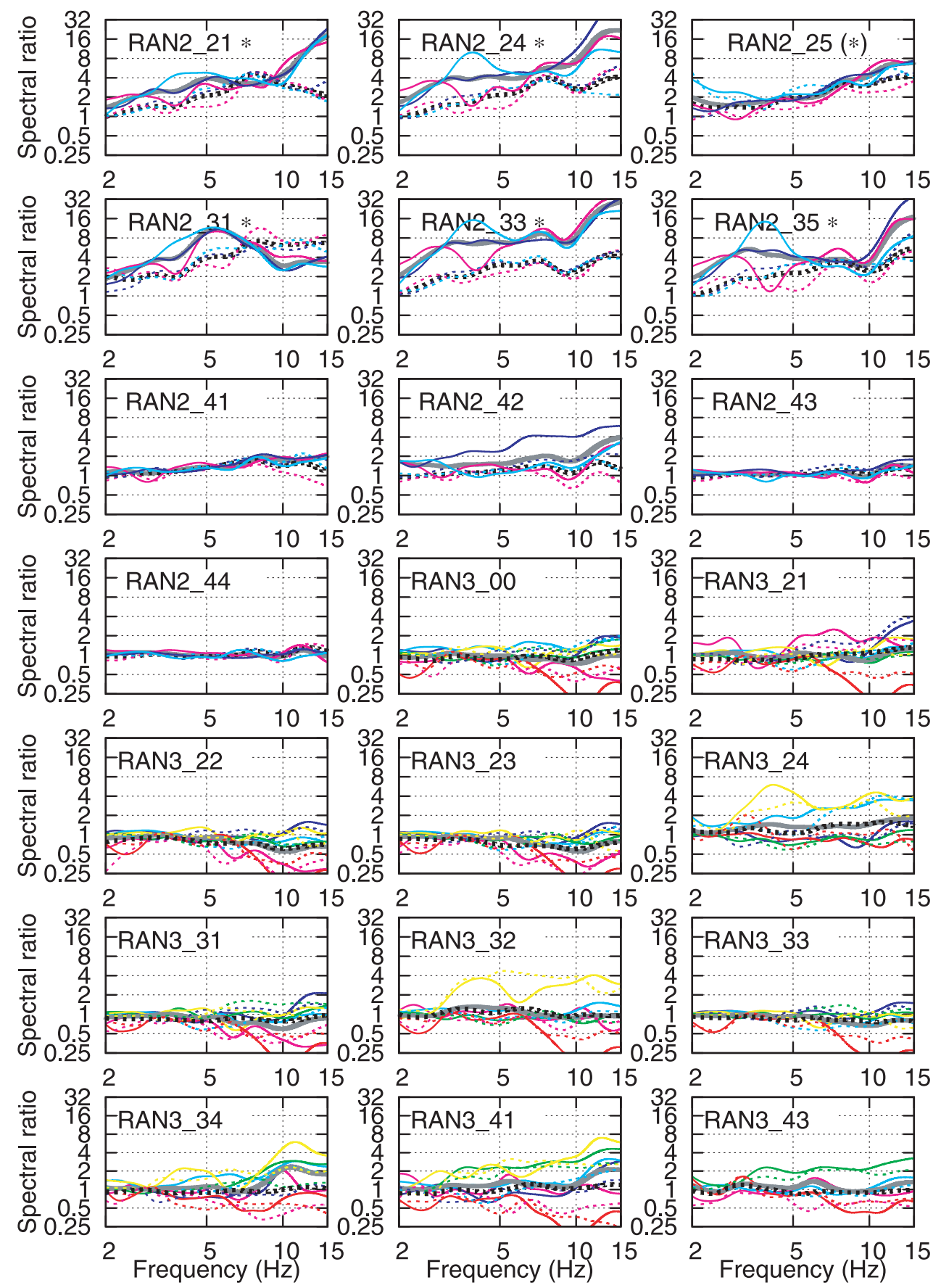

Figure 3. Site-to-reference spectral ratios for two horizontal components of ground motion ( $125^{\circ}$ azimuth - solid lines, $35^{\circ}$ azimuth - dashed lines). Colours distinguish between different events. Grey and black thick lines denote the geometric mean ratio across all events for the horizontal components $\left(125^{\circ}, 35^{\circ}\right)$, respectively. The sites within the unstable area (according Willenberg et al. 2008b) are marked by an asterisk. Station RAN2_25 was located at the border between stable and unstable areas.

analytical signals of a three-component seismogram. No explicit time-averaging is necessary in this procedure.

In this paper, we simply generalize the procedure from time to time-frequency domain by adopting a continuous wavelet transform (CWT). CWT has been used in the past for estimating timefrequency dependent polarization by Kulesh et al. (2007), who modified the standard covariance method (e.g. Kanasewich 1981). Here we use an analytical signal (Vidale 1986), which makes the analysis formally simpler by relaxing the explicit time averaging. The differences between the standard covariance method and the method adopting an analytical signal are discussed by Greenhalgh et al. (2005).

The continuous wavelet spectrum of the $i$ th seismogram component $x_{i}$ at time $t$ and scale $s$ is defined by

$W_{i}(t, s)=\frac{1}{\sqrt{|s|}} \int_{-\infty}^{+\infty} x_{i}(\tau) \psi^{*}\left(\frac{\tau-t}{s}\right) \mathrm{d} \tau$,

where $\psi$ is the mother wavelet, and the asterisk denotes complex conjugation. In particular, we use the Morlet wavelet, which is an analytical signal itself (e.g. Torrence \& Compo 1998). If the CWT 

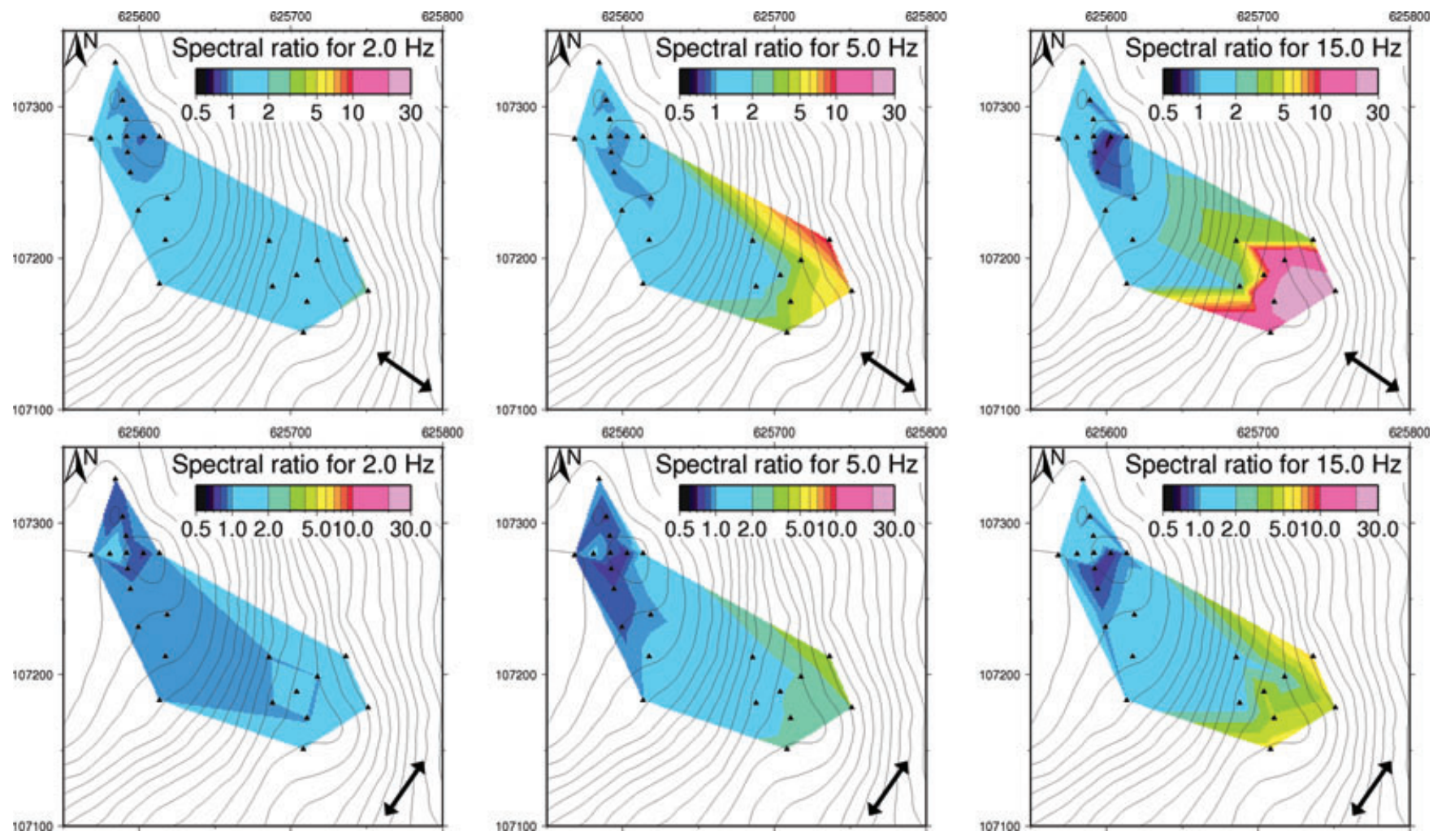

Figure 4. Map of mean site-to-reference spectral ratios for both horizontal components of ground motion ( $125^{\circ}$ azimuth upper row, $35^{\circ}$ azimuth lower row) and for three different frequencies $(2,5$ and $15 \mathrm{~Hz})$. A triangulation was used for the interpolation. Black double headed arrows indicate assumed directions $\left(125^{\circ}, 35^{\circ}\right.$ azimuths $)$ of horizontal components.

is calculated for all three components of the seismogram in the same way (i.e. using the same set of times and scales), then the coherency matrix $\widehat{C}$ can be generalized as

$\widehat{C}(t, s)=\left(\begin{array}{ccc}W_{1}^{*} W_{1} & W_{2}^{*} W_{1} & W_{3}^{*} W_{1} \\ W_{1}^{*} W_{2} & W_{2}^{*} W_{2} & W_{3}^{*} W_{2} \\ W_{1}^{*} W_{3} & W_{2}^{*} W_{3} & W_{3}^{*} W_{3}\end{array}\right)$,

where $W_{i}=W_{i}(t, s)$ is the continuous wavelet spectrum defined in eq. (1), assuming a Morlet wavelet as the mother wavelet $\psi$ (the procedure is generally valid for any mother wavelet that is also an analytical signal). The procedure is the same as in Vidale (1986), except all the retrieved polarization parameters (e.g. the strike of the direction of maximum polarization) depend also on wavelet scale $s$, which is related to the Fourier frequency. Following Vidale (1986), eigenvalues and eigenvectors of the coherency matrix $\widehat{C}$ are then calculated. The normalized eigenvector $\left(x_{1}, x_{2}, x_{3}\right)$ associated with the largest eigenvalue points in the direction of the largest amount of polarization. The phase in the complex plane of the eigenvectors is initially arbitrary. An optimum phase $(\alpha)$ is then found maximizing $X$, the length of the real component of the eigenvector

$X=\sqrt{\sum_{k=1}^{3}\left[\Re\left(x_{k} \cos \alpha+i x_{k} \sin \alpha\right)\right]^{2}}$,

where $i$ is the imaginary unit and denotes the real part. The optimum phase $\left(\alpha_{0}\right)$ is found by a grid search over the interval $(0, \pi)$. The eigenvector $\left(x_{1}, x_{2}, x_{3}\right)$ is then rotated in the complex plane by the angle $\alpha_{0}$, that is,

$\tilde{x}_{k}=x_{k}\left(\cos \alpha_{0}+i \sin \alpha_{0}\right)$.
Next the elliptical component of the polarization is estimated by

$P_{E}=\frac{\sqrt{1-X_{0}^{2}}}{X_{0}}$,

where $X_{0}$ is the length of the real component of the vector $\left(\tilde{x}_{1}, \tilde{x}_{2}, \tilde{x}_{3}\right) . P_{E}$ equal to zero indicates linearly polarized motion, $P_{E}$ equal to one indicates circularly polarized motion. The strike of maximum polarization is

$\phi=\frac{\pi}{2}-\tan ^{-1} \frac{\Re\left(\tilde{x}_{2}\right)}{\Re\left(\tilde{x}_{1}\right)}$,

and the dip of the direction of maximum polarization is

$\delta=\tan ^{-1} \frac{\Re\left(\tilde{x}_{3}\right)}{\sqrt{\left[\Re\left(\tilde{x}_{1}\right)\right]^{2}+\left[\Re\left(\tilde{x}_{2}\right)\right]^{2}}}$.

The strike defined in eq. (6) ranges from 0 to $\pi$, whereas the dip defined in eq. (7) ranges from $-\pi / 2$ to $\pi / 2$. The strike and dip angles describe the direction of maximum polarization in a 3-D half-space (dip: inclination from horizontal plane, strike: azimuth in horizontal half-plane, i.e. strikes of vectors $\left(x_{1}, x_{2}, x_{3}\right),\left(-x_{1}\right.$, $-x_{2},-x_{3}$ ) would be same). Note that all quantities in the equations presented above depend on both time $(t)$ and scale $(s)$.

\subsubsection{Results}

A window of ambient noise was selected for each station from Array 1 (subarray 2) and for the reference station. The duration of the time window ranged from 5 to 15 min depending on the presence of artificial noise. We avoided time windows including human disturbances (e.g. someone walking close to the sensor). Note 


\section{Strike - RAN1_31}

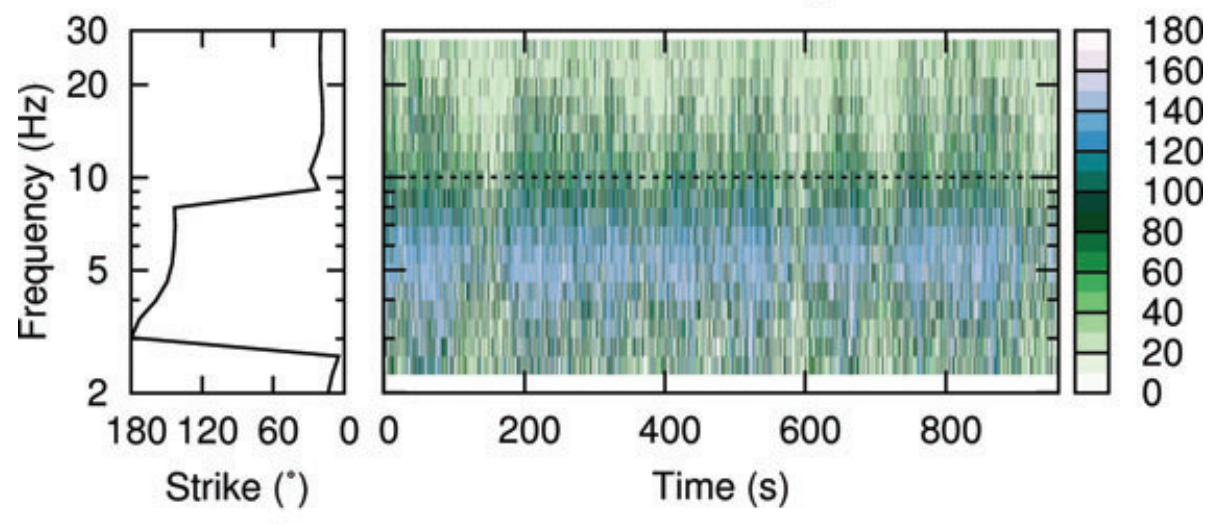

Ellipticity - RAN1_31

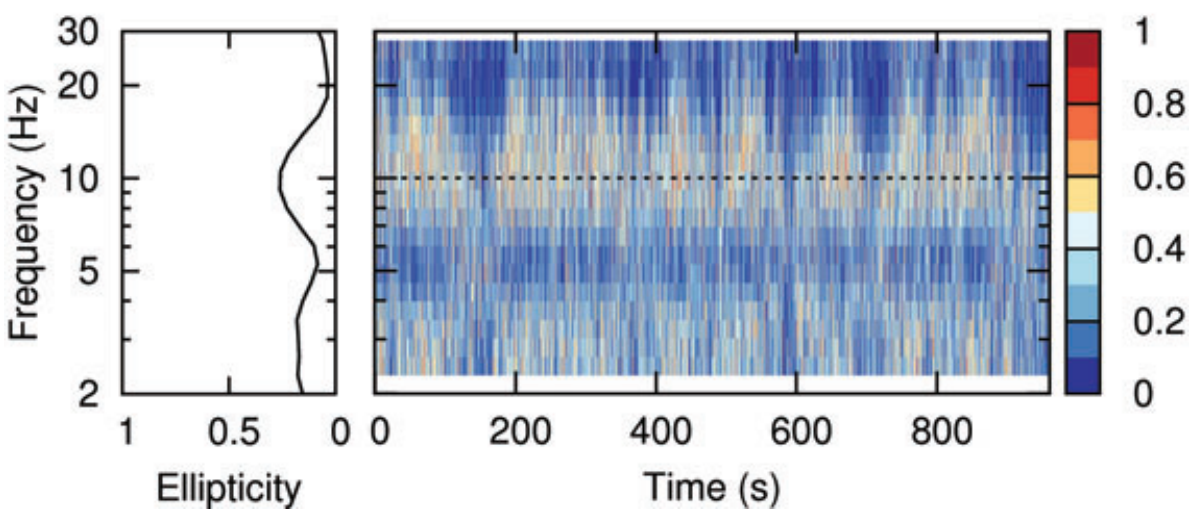

Figure 5. Strike of the direction of maximum polarization (up) and the ellipticity component (bottom) of ambient noise in the time-frequency representation for station RAN1_31. Dashed line delimits low- and high-frequency regions. Plots on the left-had side show the frequency dependencies of maximum relative occurrence in time.

that some stations of Array 2 shared positions with the stations of Array 1, and these stations have the same station number (e.g. RAN1_31 and RAN2_31, see Fig. 1). A direct comparison of site-to-reference spectral ratios and the results of noise polarization analysis could be made for these stations. We estimated the time-frequency dependence of both strike and dip of the maximum polarization and ellipticity component (in short: strike, dip and ellipticity). The dip was close to zero for all stations, which indicates that the ground motion was polarized in the horizontal plane. An example of time-frequency representation of strike and ellipticity for a single station is shown in Fig. 5. A frequency of $10 \mathrm{~Hz}$ represents roughly the boundary between two distinct regions of well-defined polarization (low ellipticity, stable value of strike). The first of these regions is centred around $5 \mathrm{~Hz}$ and the second around $20 \mathrm{~Hz}$. A similar pattern was also found at other stations. The results of polarization analyses of ambient noise are stable in time, contrasting to the estimates of site-to-reference spectral ratios obtained from the noise (discussed earlier).

The frequency distribution of strikes (i.e. histograms of directions over the time-frequency domain) are presented for all analysed recordings in Fig. 6. Contributions to these frequency distributions were weighted by the amplitude of the wavelet spectrum at each time and scale. Two frequency bands were assumed to distinguish properties of low- $(2-10 \mathrm{~Hz}, \mathrm{LF})$ and high-frequency $(10-30 \mathrm{~Hz}$, HF) parts of the signal. The LF histograms of strikes follow a distribution with well defined maxima between 120 and $140^{\circ}$ for most of the stations in the unstable area. For stations RAN1_23 and
RAN1_31, LF histograms follow bimodal distributions. One peak is again close to $140^{\circ}$, while the second peak coincides with the peak of the HF histogram. The main contribution to this second LF peak has an origin at very low frequencies $(2-3 \mathrm{~Hz})$, where the direction of maximum polarization tends towards the direction observed in HF parts of the signal (see Fig. 5, RAN2_31). The HF histograms generally follow different distributions, but again have a well-defined maximum for most stations. The maxima of HF histograms are not as consistent across stations as in the LF case; most fall in the range of $100-120^{\circ}$. Stations RAN1_23, RAN1_31, and RAN1_34 show notably different polarization at high frequencies $\left(80^{\circ}, 20^{\circ}\right.$ and $5^{\circ}$, respectively). The reference and RAN1_25 stations show no or very weak directionality, respectively for both frequency ranges.

\subsection{Discussion}

Both the site-to-reference spectral ratios and the polarization analysis showed consistent results: directionality of the spectral ratios is very close to the directions retrieved from the noise polarization analysis. The decrease of the $125^{\circ}$ component of spectral ratio for station RAN2_31 is caused by a change in the directionality with frequency that is also found in the polarization of the noise.

Concerning spectral ratios, it is not clear whether these ratios could be directly understood as estimates of amplification. First, the number of observed events was low and the signal to noise ratio was also low. Sites where the highest ratios were observed 

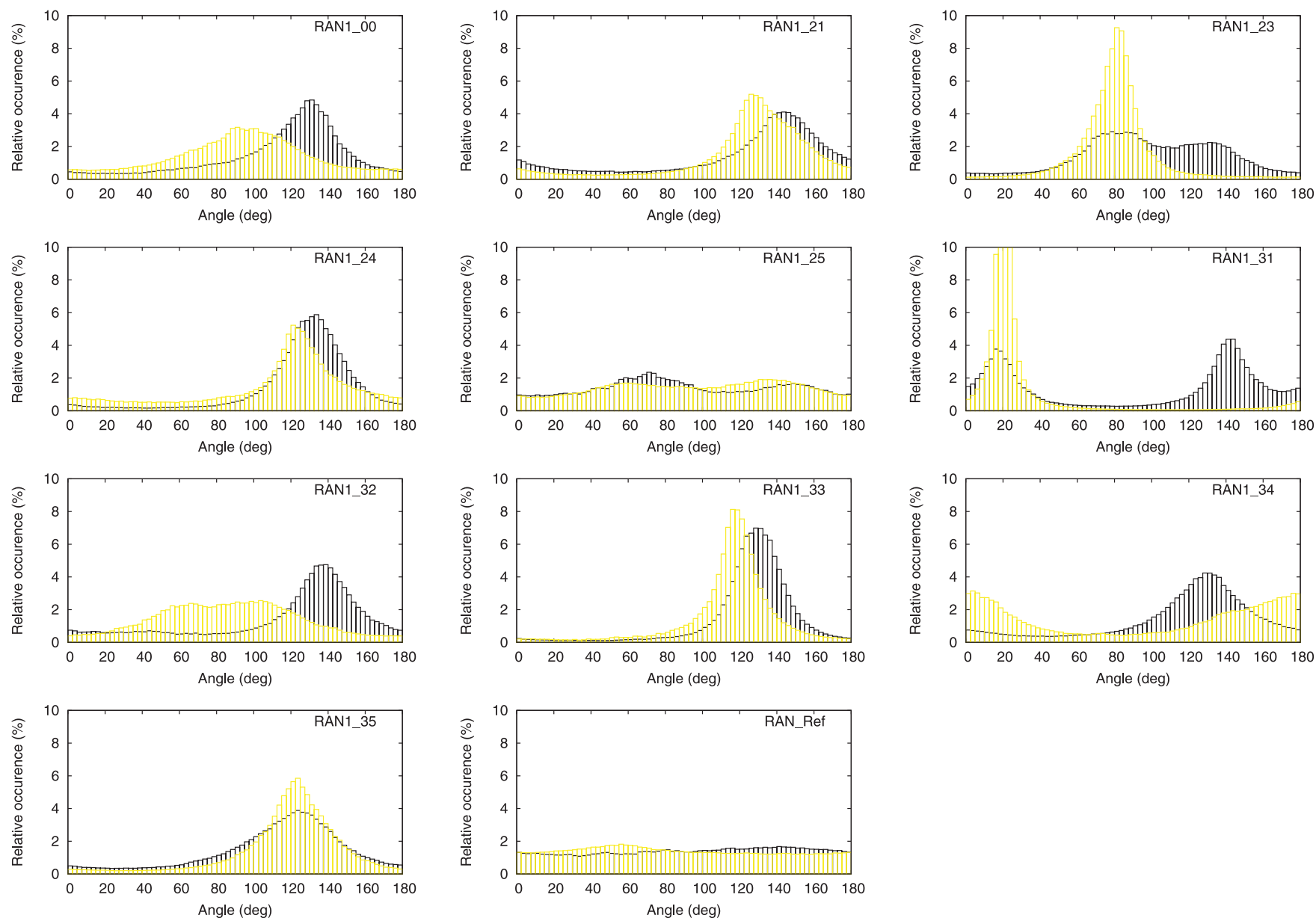

Figure 6. Relative frequencies of occurrence of the strike of ambient noise maximum polarization in time-frequency domain for frequency ranges: $2-10 \mathrm{~Hz}$ (black), $10-30 \mathrm{~Hz}$ (yellow).

were noisy, and the existence of natural local sources cannot be neglected in such an environment (heavily fractured rock). In order to resolve this issue, two semi-permanent stations have been installed at the Randa site to record events with better signal to noise ratio. Nevertheless, amplification is expected since low $P$-wave velocities were observed within the unstable area $\left(500 \mathrm{~m} \mathrm{~s}^{-1}\right.$, Spillmann et al. 2007). Moreover, the observed spectral ratios give valid qualitative indication of slope stability/instability (see Fig. 4). Note that the transition of spectral ratios from stable to unstable areas is rather smooth, so that a clear boundary cannot be distinguished between stable and unstable ground. Polarization analysis of the noise seems to be more sensitive to this boundary (as discussed later).

The observed directionality pattern of ambient noise is complex. Generally, several cases of directional site effects have been reported in the literature (e.g. Bonamassa \& Vidale 1991; Spudich et al. 1996; Del Gaudio \& Wasowski 2007). However, the origin of such directionality is still not well understood. Del Gaudio \& Wasowski (2007), who analysed records acquired on unstable slopes, ascribe the directionality phenomenon to the combined influence of topographic and geologic factors. In our study, we took advantage of the fact that the site was already extensively investigated with a broad spectrum of methods. In Fig. 7, we plot the observed directionality together with the results of in situ deformation measurements (after Willenberg et al. 2008b) to suggest a possible explanation.

Low-frequency directionality of ambient noise (the maxima of the LF histograms, black arrows) shows excellent agreement with displacement measurements. It is likely that the entire unstable rock mass vibrates in this direction of freedom $\left(130 \pm 10^{\circ}\right)$, and that the motion during a strong earthquake would be amplified in this direction. This directional movement was found to be linked to a frequency of around $5 \mathrm{~Hz}$ (see Fig. 5), which could be a resonant frequency instable rock mass, although a narrow peak is not observed in spectral ratios (see Fig. 3).

High-frequency directionality is more complex (yellow arrows in Fig. 7). Let us first focus on station RAN1_31, which shows the strongest high-frequency directionality (Fig. 5). The direction of $20^{\circ}$ (maximum of the HF histogram) is in remarkable agreement with the direction of displacement measured across the nearby surface crack, Z10. Similarly, high-frequency directionality $\left(80^{\circ}\right)$ of station RAN1_23 is in good agreement with the displacement direction of another open crack less than $10 \mathrm{~m}$ away. On the other hand, station RAN1_34, which was even closer to this crack shows directionality oriented at $4^{\circ}$. However, the peak of the HF histogram is quite broad for station RAN1_34 compared to the other two cases. Highfrequency directionality is not fixed to one common frequency for all stations, but changes from station to station in the frequency range of 10-30 Hz. Such observations lead us to hypothesize that high-frequency motion is controlled by the vibration of smaller blocks with both different resonant frequencies and directions of freedom.

Polarization analysis of the ambient noise could be used for quick, qualitative indication of stable and unstable areas of the slope. The 


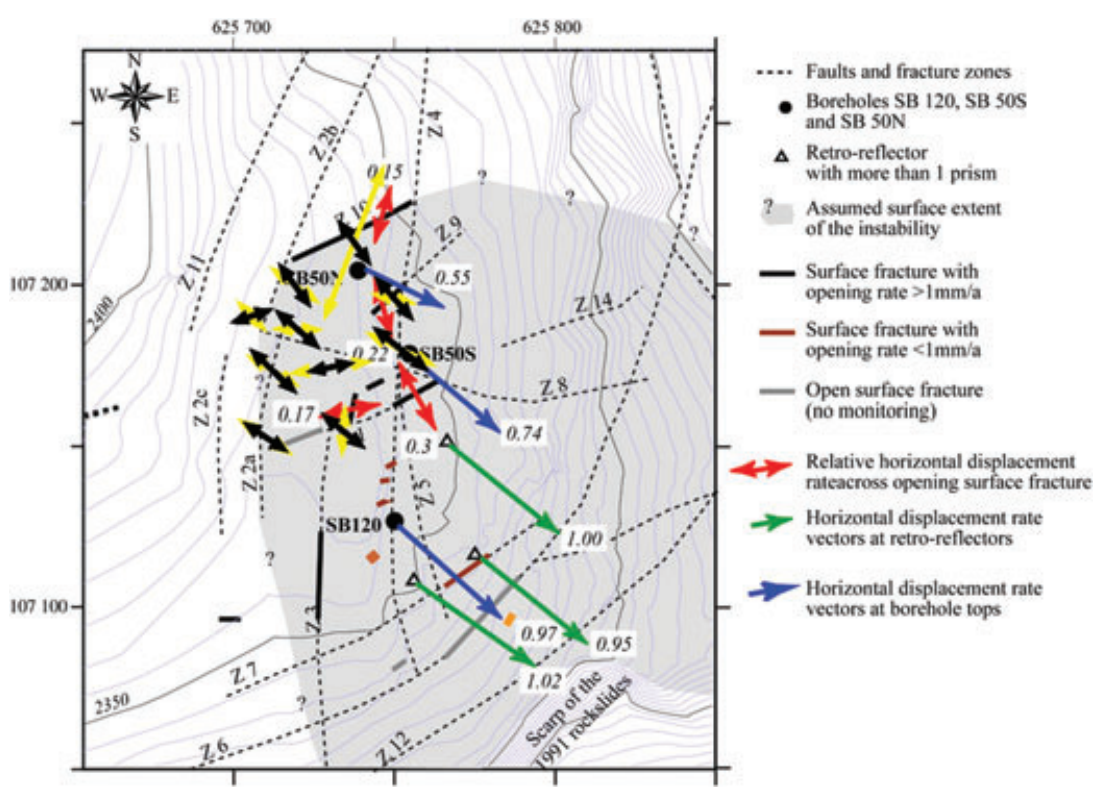

Figure 7. Map of horizontal surface displacement rates (modified after Willenberg et al. 2008b). Black and yellow arrows indicate the directions of maximum polarization of ambient noise determined in this study. Particularly, black and yellow double-headed arrows indicate the most frequent direction for 2-10 and $10-30 \mathrm{~Hz}$ frequency bands, respectively (see Fig. 6). Lengths of these arrows were scaled according to maxima of the histograms.

reference station which was located within the stable area showed no directionality. Also station RAN1_25, which was located just outside the border of unstable part proposed by Willenberg et al. (2008b), shows almost no directionality. On the other hand, stations located less than $20 \mathrm{~m}$ from RAN1_25, within the unstable area, show strong directionality. Thus, directionality appears to be a sensitive indicator of unstable areas and may be useful for mapping other instabilities.

Let us now introduce a possible physical model which helps further explain our observations. We suggest that we are able to observe a vibrational normal mode of the unstable rock mass. A specific particle motion in a narrow frequency band and its characteristic change in space are signs of a normal mode, from which one can determine both the frequency and shape of the mode (Roten et al. 2006). It is common practice to extract normal modes of civil structures from ambient vibrations measurements (e.g. Carder 1936). Normal modes can also be identified in ambient vibrations of deep sedimentary basins (Roten et al. 2006; Roten \& Fäh 2007). Our present observation is similar: within the unstable portion of the slope ambient noise becomes polarized in one direction and frequency band for all stations. Willenberg (2004) studied different mechanical models of current slope instability in Randa and compared observed and modelled deformations. All models included a number of parallel dipping faults. These faults are perpendicular to the direction of deformation observed on the surface and generally reduce the bulk stiffness of the rock mass. $P$-wave velocities as low as $500 \mathrm{~m} \mathrm{~s}^{-1}$ were observed at shallow depths $(<25 \mathrm{~m})$ where the rock is most deformed and highly fractured (Spillmann et al. 2007). Thus, the unstable rock mass could be viewed as a volume of effectively reduced elastic moduli, analogous to the sediment infill in valleys. If we assume that the stiffness of the rock is reduced anisotropically, primarily in the direction of deformation, then the fundamental mode shape may also be pronounced in this direction.

Higher site-to-reference spectral ratios around $5 \mathrm{~Hz}$ towards the scarp are also in agreement with the hypothesis of normal mode. We find two supporting concepts from studies of resonance phenomenon in sedimentary basins: (1) Fundamental modes of sed- imentary basins have the highest amplitude in areas where the sediment is deepest (e.g. Roten et al. 2006). At Randa, the thickness of highly fractured rock increases towards the rockslide scarp (Willenberg 2004), thus the highest amplitudes are also expected in this region. (2) Fundamental modes have the highest amplitude towards the centre of the valley (analogous to a string fixed on both ends). In our case of the Randa rock slope instability, because the geometry is quite different from a basin and the cliff acts like a free face, the highest amplitudes should be expected at the scarp (analogous to a string fixed at just one end). Nevertheless, numerical modelling should be performed in the future to fully understand the shape of such normal modes.

Modal frequencies present a useful constraint on material properties of the structure under study, for example, Roten \& Fäh (2007) in the case of sedimentary basins; Michel et al. (2008) for investigation of buildings. As the depth of the instability at Randa is not well constrained, it is difficult to estimate the elastic parameters of the unstable rock mass. However, fundamental frequency analysis may present a promising constraint either on the extent or the effective material properties of the future rockslide.

\subsection{Conclusions}

Ambient noise measurements on an unstable rock slope presented in this paper were shown to be useful for rapidly obtaining spatial information regarding the instability structure. Although we were unable to retrieve shear wave velocity profiles, it was possible to gain unique information on the seismic response of a future landslide. The wavefield within the unstable rock mass appears to be dominated by normal modes of the rock blocks rather than horizontal propagation of seismic waves. Techniques developed in this work could be used in the future to quickly and inexpensively map certain structural features of rock slope instabilities. In particular, it is possible to distinguish unstable areas, the direction of bulk slope deformation, and the activity of surface cracks. Further, a possible fundamental frequency of the unstable rock mass was identified, which could be used in the future to constrain either the extent or 
the effective material properties of the instability. It is necessary in the future to confirm these hypotheses by measurements at different landslide locations and through supporting numerical modelling of the system normal modes. This study also shows that interpretation of only a single measurement of seismic motion at a similar rock slope instability would likely give biased results, as the characteristics of motion change rapidly from point to point.

\section{ACKNOWLEDGMENTS}

We would like to thank Andrew Curtis, Robert van Vossen and anonymous reviewer for constructive comments and helpful reviews. This research is part of the COGEAR project, funded by the Competence Center Environment and Sustainability of the ETH Domain (CCES) and was also supported by the project NERIES (Network of Research Infrastructures for European Seismology, task JRA4 - 'Geotechnical site characterization'). Wavelet software was provided by C. Torrence and G. Compo, and is available at URL: http://paos.colorado.edu/research/wavelets/. Some figures in this paper were made using Generic Mapping Tools (GMT) 4 software written by Wessel \& Smith (1998).

\section{REFERENCES}

Bonamassa, O. \& Vidale, J.E., 1991. Directional site resonances observed from aftershocks of the 18th October 1989 Loma Prieta earthquake, Bull. seism. Soc. Am., 81, 1945-1957.

Borcherdt, R.D., 1970. Effects of local geology on ground motion near San Francisco Bay, Bull. seism. Soc. Am., 60, 29-61.

Carder, D.S., 1936. Observed vibration of buildings, Bull. seism. Soc. Am., 26, 245-277.

Del Gaudio, V. \& Wasowski, J., 2007. Directivity of slope dynamic response to seismic shaking, Geophys. Res. Lett., 34, L12301, doi:10.1029/2007GL029842.

Danneels, G., Bourdeau, C., Torgoev, I. \& Havenith, H.-B., 2008. Geophysical investigation and dynamic modelling of unstable slopes: case-study of Kainama (Kyrgyzstan), Geophys. J. Int., 175, 17-34, doi:10.1111/j.1365246X.2008.03873.x.

Fritsche, S., Fäh, D., Gisler, M. \& Giardini, D., 2006. Reconstructing the Damage Field of the 1855 Earthquake in Switzerland: historical investigations on a well-documented event. Geophys. J. Int., 166, 719-731.

Green, A.G., Maurer, H.R., Spillmann, T., Heincke, B. \& Willenberg, H., 2006. High-resolution geophysical techniques for improving hazard assessments of unstable rock slopes, The Leading Edge, 25, 311-316.

Greenhalgh, S., Mason, I.M. \& Zhou, B., 2005. An analytical treatment of single station triaxial seismic direction finding, J. Geophys. Eng., 2, 8-15.

Kanasewich, E.R., 1981. Time Sequence Analysis in Geophysics, University of Alberta Press, Edmonton, Alberta.

Keefer, D.K., 1984. Landslides caused by earthquakes, Geol. Soc. Am. Bull., 95, 406-421.

Kind, F., F äh, D. \& Giardini, D., 2005. Array measurements of S-wave velocities from ambient vibrations, Geophys. J. Int., 160, 114-126.
Konno, K. \& Ohmachi, T., 1998. Ground-motion characteristics estimated from spectral ratio between horizontal and vertical components of microtremor, Bull. seism. Soc. Am., 88, 228-241.

Kulesh, M., Diallo, M., Holschneider, M., Kurennaya, K., Krüger, F., Ohrnberger, M. \& Scherbaum, F., 2007. Polarization analysis in wavelet domain based on the adaptive covariance method, Geophys. J. Int., 170, 667-678, doi:10.1111/j.1365-246X.2007.03417.x.

Michel, C., Guéguen, P. \& Bard, P.-Y., 2008. Dynamic parameters of structures extracted from ambient vibration measurements: an aid for the seismic vulnerability assessment of existing buildings in moderate seismic hazard regions, Soil. Dyn. Earthquake Eng., 28, 593-604.

Newmark, N., 1965. Effects of earthquakes on dams and embankments, Geotechnique, 15, 139-160.

Okada, H., 2003. The Microtremor Survey Method, Geophysical Monograph Series, no. 12, Society of Exploration Geophysicists, Tulsa.

Roten, D. \& Fäh, D., 2007. A combined inversion of Rayleigh wave dispersion and 2-D resonance frequencies, Geophys. J. Int., 168, 1261-1275.

Roten, D., Cornou, C., Fäh, D. \& Giardini, D., 2006. 2D resonances in Alpine valleys identified from ambient vibration wavefields, Geophys. J. Int., 165, 889-905.

Schindler, C., Cuénod, Y., Eisenlohr, T. \& Joris, C.L., 1993. Die Ereignisse vom 18. April und 9. Mai 1991 bei Randa (VS) — ein atypischer Bergsturz in Raten. Eclogae geol. Helv., 86, 643-665.

Spillmann, T., Maurer, H.R., Willenberg, H., Evans, K.F., Heincke, B. \& Green, A.G., 2007. Characterization of an unstable rock mass based on borehole $\operatorname{logs}$ and diverse borehole radar data, J. appl. Geophys., 61, 16-38.

Spudich, P., Hellweg, M. \& Lee, W.H.K., 1996. Directional topographic site response at Tarzana observed in aftershocks of the 1994 Northridge, California, earthquake: implications for mainshock motions, Bull. seism. Soc. Am., 86, S193-S208.

Terzaghi, K., 1950. Mechanism of landslides, in Application of Geology to Engineering Practice: Berkey Volume, pp. 83-122, ed. Paige, S., Geologic Society of America, Baltimore.

Tokimatsu, K., 1997. Geotechnical site characterization using surface waves, in Proc. 1st Intl. Conf. Earthquake Geotechnical Engineering, Vol. 3, pp. 1333-1368, ed. Ishihara, K., Balkema.

Torrence, C. \& Compo, G.P., 1998. A practical guide to wavelet analysis, Bull. Am. Meteorol. Soc., 79, 61-78.

Vidale, J.E., 1986. Complex polarisation analysis of particle motion, Bull. seism. Soc. Am., 76, 1393-405.

Wessel, P. \& Smith, W.H.F., 1998. New, improved version of the Generic Mapping Tools released, EOS, Trans. Am. geophys. Un., 79, 579.

Willenberg, H., 2004. Geologic and kinematic model of a landslide in crystalline rock (Randa, Switzerland), PhD thesis, Swiss Federal Institute of Technology, Z ürich.

Willenberg, H., Loew, S., Eberhardt, E., Evans, K.F., Spillmann, T., Heincke, B., Maurer, H.R. \& Green, A.G., 2008a. Internal structure and deformation of an unstable crystalline rock mass above Randa (Switzerland). Part I: internal structure from integrated geological and geophysical investigations, Eng. Geol., 101, 1-14.

Willenberg, H., Evans, K.F., Eberhardt, E., Spillmann, T. \& Loew, S., 2008 b. Internal structure and deformation of an unstable crystalline rock mass above Randa (Switzerland). Part II: three-dimensional deformation patterns, Eng. Geol., 101, 15-32. 